\title{
Investigation of the moderate toxicity of agricultural pesticides cyantraniliprole, boscalid and spiromesifen in vitro using neurotoxicity screening test
}

\author{
Emine Müge Karakayalı ${ }^{1}$ (D), Duygu Kekeç ${ }^{1}$ (D), Tuna Önal ${ }^{2}$ (D), İbrahim Tuğlu ${ }^{2}$ \\ ${ }^{1}$ Department of Medical Microbiology, School of Medicine, İzmir Democracy University, Izmir, Turkey \\ ${ }^{2}$ Department of Histology and Embryology, School of Medicine, Manisa Celal Bayar University, Manisa, Turkey
}

\begin{abstract}
Objectives: Although industrial products used as agricultural pesticides are considered safe, they are likely to lead to chronic problems due to their long-term effects. The neurotoxicity screening test (NST) is a method based on the inhibition of neurite extension of neurons that do not not die with toxic effects. In this study, we aimed to investigate the moderate neurotoxic effects and reveal the potential dangers of agricultural pesticides in vitro using NST.

Methods: Cyantraniliprole, boscalid and spiromesifen were used as agricultural pesticides on the mouse neuroblastoma cell line N2a. Neurite extension of neurons was performed by taking them into the proliferation medium followed by the differentiation medium. Cell viability and proliferation were analyzed using the MTT test. The percentage of neurite inhibition was calculated by measuring neurite outgrowth by NST. Oxidative stress was analyzed by NOS staining with h-score and apoptosis was shown using the apoptotic index in TUNEL staining.

Results: Cyantraniliprole, boscalid and spiromesifen at high concentrations caused neurite inhibition, decreased proliferation and reduced the viability of cultured neurons. These agricultural pesticides were found to be significantly moderate toxic for neurons by increasing oxidative stress and apoptosis.

Conclusion: We conclude neurite inhibition may be important in early recognition for detecting and preventing the neurotoxic effect of pesticides, and NST is an important in vitro test that can predict the long-term effects of neurotoxic agents. In the present study, we observed cyantraniliprole, boscalid and spiromesifen had moderate neurotoxic effects in varying degrees using NST. This means that pesticides may behave toxic even in permissible limits for chronic exposure.
\end{abstract}

Keywords: agricultural pesticide; apoptosis; environmental toxicity; MTT, neurotoxicity screening test

Anatomy 2020;15(1):1-10 @2021 Turkish Society of Anatomy and Clinical Anatomy (TSACA)

\section{Introduction}

Agricultural pesticides are neglected in terms of their effect on environmental pollution due to their increasing use and their being considered safe. Environmental pollution caused by agricultural pesticides at acceptable doses does not seem to be a problem. However, in the long-term use, their slow accumulation may lead to moderate neurotoxic effects that can be observed in the long term. ${ }^{[1,2]}$ In the present study, the moderate neurotoxic effects of agericultural pesticides such as cyantraniliprole (CP), boscalid (BC) and spiromesifen (SM) were investigated in vitro.
$\mathrm{CP}$ is a new second-generation ryanodine receptor insecticide. Its pesticidal effect is through unregulated activation of insect ryanodine receptor channels. This effect causes internal calcium store depletion and disorganized muscle contraction, paralysis and death of the insect. ${ }^{[1,3]}$ A previous study used inhalation 1C50 dose as $5.2 \mathrm{mg} / \mathrm{lt}$ for the rat. ${ }^{[4]}$

$\mathrm{BO}$ is a fungicide in agriculture and detected in both environments and agricultural products. $\mathrm{BO}$ is thought to be safe for neurotoxic effects. BO induced developmental 
defects related to oxidative stress with alteration of ATPase activity in zebrafish embryos. ${ }^{[5]}$ Moreover, $\mathrm{BO}$ also caused disruption of motion and locomotor function in larval fish. ${ }^{[6,7]}$ These results provide a warning for its residues in environment and agricultural products. It was also shown that $\mathrm{BO}$ was neurotoxic for primary cultured cortical neurons at low level of exposure for several days at doses 0.1 and $100 \mu \mathrm{M}$ for 7 days. ${ }^{[5]}$ Moreover, another study showed that $\mathrm{BO}$ was also toxic to human lymphocytes. ${ }^{[7]}$

$\mathrm{SM}$ is novel insecticide belonging to the chemical class of tetronic and tetramic acid derivatives. It is very effective on Bemisia tabaci around the world. ${ }^{[8,9]}$ SM was toxic for rat hepatocytes at $3 \mathrm{mg} / \mathrm{kg} \cdot{ }^{[3]}$ However, there was no toxic signs in acute, subchronic and chronic neurotoxicity in rats. The long-term rat studies revealed no indications for neurotoxic or immunotoxic potential of SM. ${ }^{[3]}$

The neurotoxicity screening test (NST) is a method based on neurite prolongation after the application of differentiation medium to neuronal cell line. ${ }^{[10]}$ After they acquire neuron characteristics, neurite prolongation inhibition occurs in cells that do not die as a result of the direct toxic effect. With the NST, products likely to have a moderate neurotoxic effect in the long term are detected. ${ }^{[1-13]}$ While the direct neurotoxic effect leads to the occurrence of decreased proliferation and necrosis, the moderate indirect neurotoxic effect which takes a long time to act induces apoptosis and neurite inhibition. Free radicals, which increase oxidative stress due to toxic effects, and intracellular signal communication are the mechanisms used in the emergence of these findings ${ }^{[14-16]}$ In this study, the moderate toxic effects of various agricultural pesticides whose safety has been proven and toxic effects are minimum were investigated with the NST.

N2a line neuronal cells are from mouse neuroblastoma. ${ }^{[1,17]}$ These neuron-like cells have been used in studies for neuronal differentiation, axonal growth, signaling pathway and neurotoxicity. ${ }^{[18]} \mathrm{N} 2 \mathrm{a}$ cells express neuronal characteristics with the presence of neurofilaments and large amounts of microtubular proteins after differentiation. They differentiate to neurons through serum deprivation with dibutyryl cyclic adenosine monophosphate (dbcAMP) in culture medium. ${ }^{[18]}$

Safe agricultural pesticide may have some moderate toxic effect such as neurite inhibition and apoptosis before they die from toxic effect. ${ }^{[14]}$ These signs are more important in chronic use. Many studies show that they have potential neurotoxicity due to chronic exposure to low doses of pesticides. Most of these works used cell culture model for chronic exposure to evaluate possible environmental toxic compounds by alterations in the sensitivity of nerve cells to subsequent acute exposure. $\mathrm{N} 2 \mathrm{a}$ neuroblastoma cells in culture were grown in the presence of various pesticides or herbicides for appropriated time. ${ }^{[4]}$ Extension of neurite-like structures was measured by light microscopy and quantitative image analysis at IC50 level. ${ }^{[17]}$ It is possible to see their potential toxicity in chronic exposure by this method. ${ }^{[4,11,14,1,2,20]}$

\section{Materials and Methods Supplies and Chemicals}

The mouse neuroblastoma (N2a) cells (cell line: 89121404) were obtained [The European Collection of Authenticated Cell Cultures (ECACC).$^{[10]}$ All the chemicals used in the experiment were obtained from Sigma (St. Louis, MO, USA). While the tissue culture flasks and culture plates were obtained from Falcon / Fred Baker (Runcorn, Cheshire, England), gentamicin was obtained from Ibrahim Etem (20 mg Genta ${ }^{\oplus}$ bulb, Ibrahim Etem, Istanbul, Turkey). ${ }^{[7,10]}$

\section{Cell Culture}

In all the experiments, different agricultural pesticides were investigated in terms of their effects on the differentiated and undifferentiated culture cells. Pesticides were dissolved in DSMO at final concentration for IC50 doses. Differentiated and undifferentiated cells were incubated with the pesticides for a further 24 hours. Neuroblastoma cells in culture medium containing $5 \%$ fetal calf serum, $5 \%$ horse serum, $25 \mu \mathrm{g} / \mathrm{mL}$ gentamicin, $1 \%$ penicillin / streptomycin solutions $(10,000 \mathrm{U} / 10 \mathrm{mg})$, Glutamax-1 and high glucose Dulbecco Modified Eagle (DMEM) were incubated at $37^{\circ} \mathrm{C}$ in a humid environment including $5 \% \mathrm{CO}_{2 .}{ }^{[21,22]}$

\section{Cell Viability}

To calculate the cell viability and growth, the MTT experiment, reduction of 3- (4.5-dimethylthiazol-2-yl) - 2.5diphenyltetrazolium bromide to a purple formazan product was used. ${ }^{[16]}$ Three wells of the 96-well culture dish were used for the evaluation of each pesticide concentration. Cell densities of $5 \times 10^{4} / \mathrm{mL}$ prepared per well were used. Pesticide-free cell medium $(100 \mu \mathrm{L})$ was used as the positive control, while cell and pesticide-free medium was used as the negative control. Cells were previously treated with the indicated concentrations for 24 and 48 hours. During the last 4 hours of the culture period tested, cells were incubated with the MTT at $37^{\circ} \mathrm{C}$ in a humidified environment including $5 \% \mathrm{CO}_{2}$. The medium was then changed, by adding $200 \mu \mathrm{L}$ of dimethyl sulfoxide (DMSO, Sigma-Aldrich) to each well to dissolve the formazan salts. Absorbance was determined at $570 \mathrm{~nm}$ in a UV-spec- 
trophotometer multi-plate reader (Versa Max, Molecular Device, Sunnyvale, CA, USA). ${ }^{[1,1,16,19,20,23-25]}$

\section{Cell Differentiation and Neurite Outgrowth}

To measure neurite outgrowth, N2a cells were placed in the proliferation medium in 24-well culture plates at a cell density of 15,000 cells $/ \mathrm{mL}$. Twenty-four hours later, cells were induced to differentiate and produce neurites in the presence of pesticides using the following method..$^{[10,18]}$ The culture medium in each well was changed to the medium containing no serum but $0.5 \mathrm{mM}$ dibutyl cyclic AMP. To measure neurite growth, pesticides at IC50 concentrations were added. Cells were incubated for a further 24 hours. Cells fixed with phosphate buffered saline (PBS) with $4 \%$ $(\mathrm{w} / \mathrm{v})$ paraformaldehyde for 10 minutes were then stained with Coomassie for 3 minutes. ${ }^{[26]}$ Blue cell dye $(0.6 \%$ [w/v] Coomassie Brilliant Blue G, 10\% [v/v] acetic acid, 10\% $[\mathrm{v} / \mathrm{v}]$ methanol and $80 \%[\mathrm{v} / \mathrm{v}]$ PBS) was washed with the PBS. Two blinded observers took the photographs of samples by using an Olympus BX-40 (Olympus, Tokyo, Japan) light microscope with a video camera (JVC-TK-C 601, Tokyo, Japan) for digital imaging. The analysis of the images was performed using the Image-Pro Plus image analyzer (5.1.259, Bioscience Technology, Bethesda, MD, USA). Ten different areas with approximately 10 cells were selected for pesticides and controls. ${ }^{[7]}$ By automatically measuring the total neurite length (in pixels) for cells in each area, the results were expressed as the average neurite length per cell..$^{[1,10,12,21]}$

\section{Oxidative Stress}

Cells were immunostained for e-NOS and i-NOS to evaluate levels of the oxidative stress. After application of OC at IC50 dose, the cells were fixed in the 4\% paraformaldehyde for $30 \mathrm{~min}$ and washed in the PBS three times for $5 \mathrm{~min}$ each. Permeabilization was performed using $0.1 \%$ Triton X-100 (A4975; AppliChem, Darmstadt, Germany) at $4^{\circ} \mathrm{C}$ for $15 \mathrm{~min}$, and cells were washed with the PBS. Endogenous peroxidase activity was inhibited using 3\% hydrogen peroxide for $5 \mathrm{~min}$. Cells were washed with the PBS and incubated with anti-eNOS rabbit polyclonal antibody (RB-1711-P1; Neomarkers, Fremont, CA, USA) diluted 1:100 and anti-i-NOS rabbit polyclonal antibody (RB-1605-P; Neomarkers) diluted 1:100 for $18 \mathrm{~h}$ at $4^{\circ} \mathrm{C}$. The cells were washed three times for $5 \mathrm{~min}$ each in the PBS, treated with biotin-streptavidin hydrogen peroxidase secondary antibody (Invitrogen-Histostain Plus Bulk Kit ${ }^{\circledR}$, 85-9043; Invitrogen) for $30 \mathrm{~min}$. After washing with PBS three times for $5 \mathrm{~min}$ each, cells were incubated with diaminobenzidine (DAB) (00-2020; Zymed, Burlingame CA, USA) for $5 \mathrm{~min}$ for immunolabeling, then counterstained with Mayer's haematoxylin (72804E; Microm,
Walldorf, Germany). Cells were covered with mounting medium (AML060; Scytek, Logan, UT; USA) and photographed using an Olympus light microscope (BX40; Tokyo, Japan). Control samples were processed identically except that the primary antibody was omitted. The immunostaining was repeated three times. The two blinded observers scored the immunostaining as 0 , no staining; 1 , weak staining; 2 , moderate staining; 3 , moderate-strong staining; 4, strong staining; 5, very strong staining. The Hscore then was calculated using the following formula: $\mathrm{H}-$ score $=\mathrm{Pi}$ intensity of staining +1 , where $\mathrm{Pi}$ is the percentage of stained cells for each intensity varying from 0 to $100 \%$. ${ }^{[1,21]}$

\section{TUNEL Assay}

Terminal deoxynucleotidyl transferase-biotin nick end labelling (TUNEL) using the DeadEnd TM Colorimetric TUNEL system (Promega, Madison, WI, USA) was used to detect apoptotic cells. After the application, the cells were fixed in $4 \%$ paraformaldehyde for $30 \mathrm{~min}$ and rinsed three times in the PBS for $5 \mathrm{~min}$. Then the cells were incubated with $20 \mu \mathrm{g} / \mathrm{mL}$ Proteinase K. for $10 \mathrm{~min}$ and washed three times again in the PBS for $5 \mathrm{~min}$. For endogenous activity inhibition, the cells were treated with 3\% hydrogen peroxide and rinsed in the PBS. Afterward, the cells which were treated with the equilibration buffer for $5 \mathrm{~min}$ incubated with Tdt-enzyme for 60 at $37^{\circ} \mathrm{C}$ than were proceeded with $2 \times$ SCC solution for $15 \mathrm{~min}$ and then washed three times in the PBS for 5 min. The streptavidin peroxidase procedure was performed for $45 \mathrm{~min}$, after which the cells were rinsed in the PBS and incubated with DAB; Mayer's haematoxylin was performed for counterstaining. The cells were than rinsed in distilled water and mounted in the mounting medium. TUNEL-positive staining was evaluated by two blind observers, under Olympus BX40 light microscope. Apoptotic index was calculated as the sum of the percentages of positively labelled cells. For TUNEL staining, each section was counted for 100 TUNEL-positive cells from the randomly chosen fields. Observers rated the percentage of apoptotic cells as 0: no apoptosis, $1: 1 \%-10 \%$ apoptosis, $2: 11 \%-25 \%$ apoptosis, 3 : 26\%-50\% apoptosis, $4: 51 \%-75 \%$ apoptosis, and 5: more than $75 \%$ apoptosis. ${ }^{[2,21,27,28]}$ The apoptotic index was counted as the percentage of the apoptotic cells relative to the total cell number.

\section{Statistical Analysis}

The results were analysed using the GraphPad (GraphPad Software, SanDiego, CA, USA) and one-way ANOVA with Tukey post hoc testing and presented as mean \pm SEM. Statistical significance was defined as $\mathrm{p} \leq 0.05$ or $\mathrm{p} \leq 0.001^{[2,20,21]}$ 


\section{Results}

N2a cells were taken into the culture medium and incubated for 24 hours to proliferate. In the second 24 hours after proliferation, N2a cells were taken to the differentiation medium for neurite elongation. Neurite elongation was shown using Coomassie staining (Figure 1). The IC50 doses of the pesticides administered in the proliferation stage and determined by the MTT were as follows: $38.44 \mu \mathrm{M}$ for CP, $55.66 \mu \mathrm{M}$ for BO and $8.12 \mu \mathrm{M}$ for SM (Figure 2a).

Neurite inhibitions of differentiated cells after the second 24 hours of application were as follows: $78.94 \pm 6.48 \%$ for CP, $86.94 \pm 7.74 \%$ for $\mathrm{BO}$, and $62.22 \pm 5.25 \%$ for $\mathrm{SM}$ (Figure 2b). Compared to the controls, pesticides were observed to have significant neurite inhibition as neurotoxic effects $(\mathrm{p}<0.05)$.
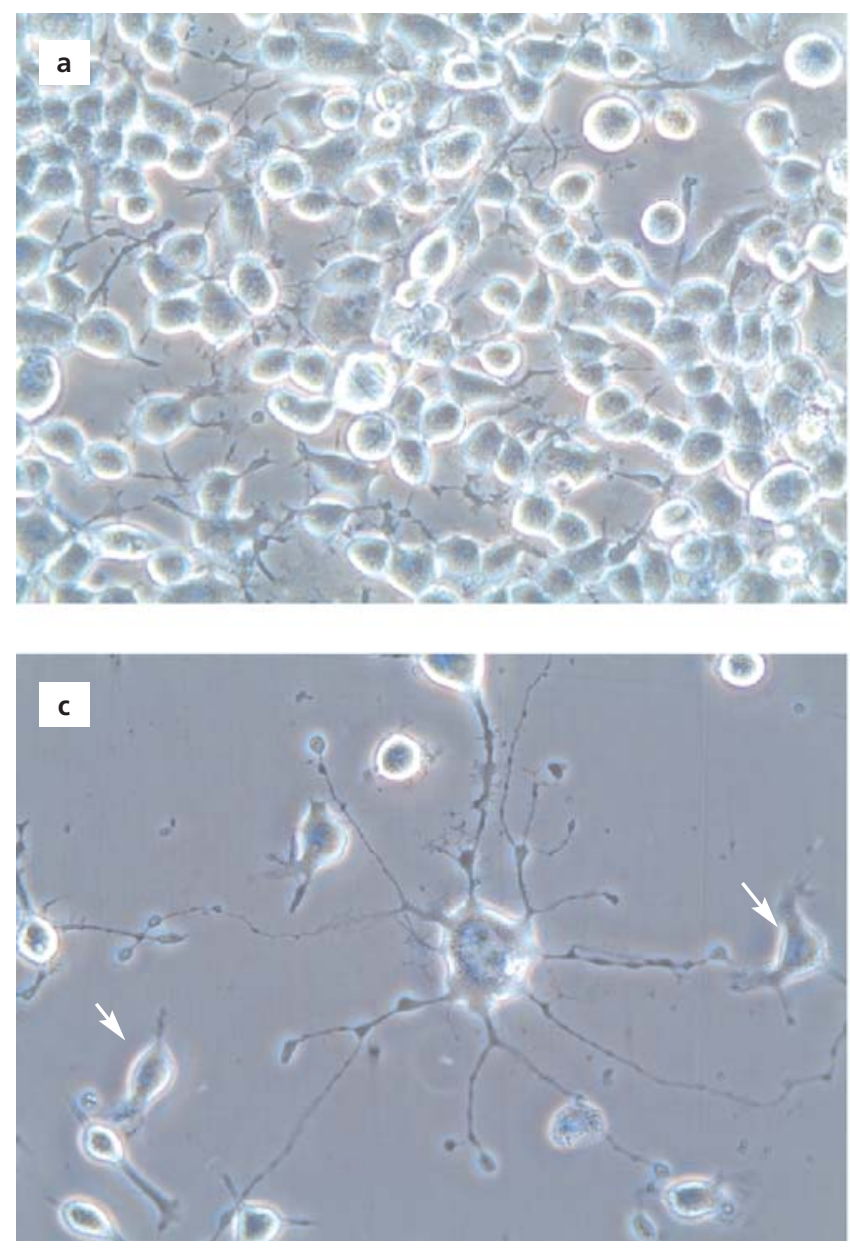

At IC50 doses, the iNOS and eNOS expressions of the cells were determined to increase both in the proliferation stage and in the neuritis inhibition stage after differentiation (Figure 3). Moreover, H score levels which increased significantly $(\mathrm{p}<0.05)$ due to oxidative stress. There was significantly more toxic effect for SM compared to those of BO $(\mathrm{p}<0.001)$ and CP $(\mathrm{p}<0.05)$ in eNOS h-score. Similarly, SM was showed significantly $(\mathrm{p}<0.001)$ more toxic effect for BO $(\mathrm{p}<0.01)$ and $\mathrm{CP}(\mathrm{p}<0.05)$ in iNOS hscore. Neurotoxic effect of BO and CP didn't differ significantly (Figure 4).

At IC50 doses, it was observed in TUNNEL labeling of cells that the apoptotic index increased both in the proliferation stage and in the neurite inhibition stage after differentiation (Figure 3). It was also observed that the apoptotic index increased significantly $(\mathrm{p}<0.05)$ due to toxic
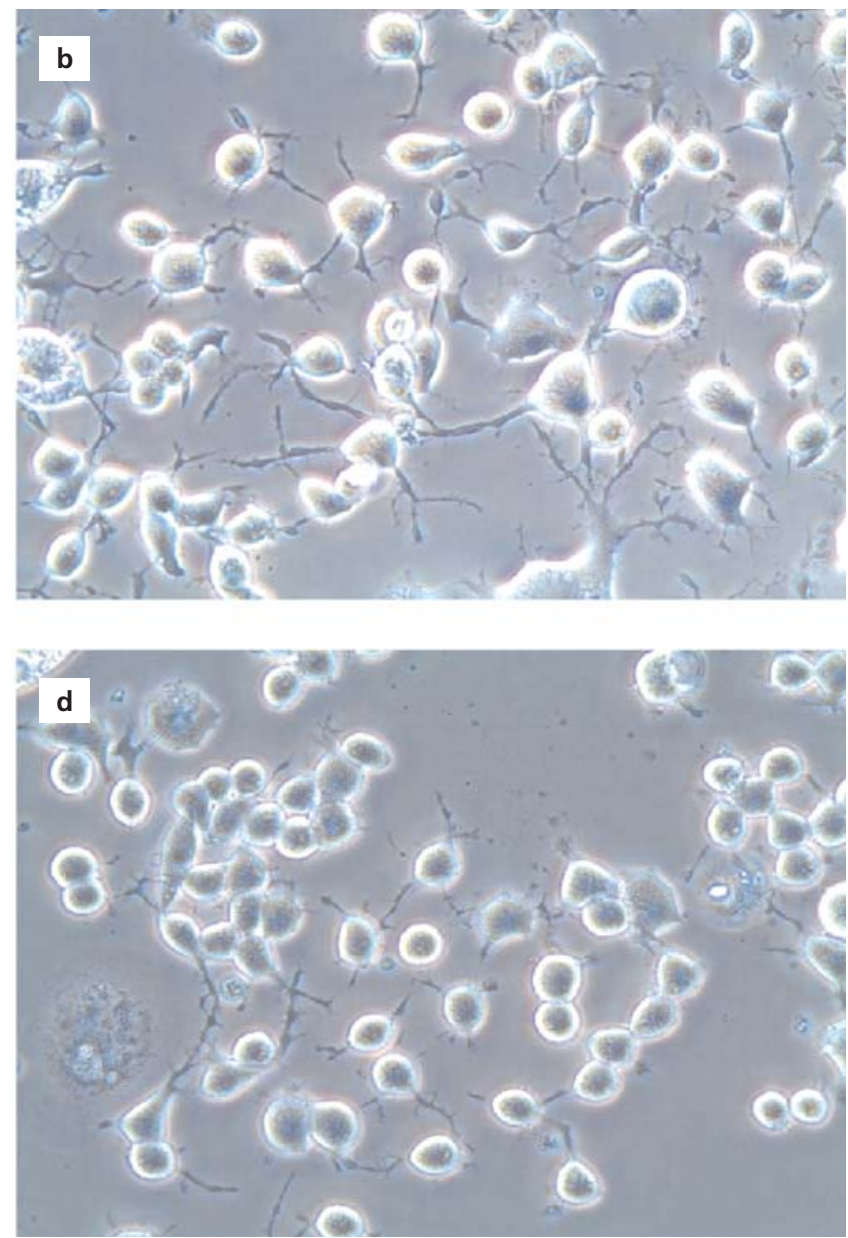

Figure 1. (a) N2a cells were taken into the culture medium and incubated for 24 hours to proliferate; (b, c) In the second 24 hours after proliferation, N2a cells were taken to the differentiation medium for neurite elongation; (d) There was neurite inhibition after application of pesticide. Coomassie staining; $\times 200$. 
agents. SM caused more apoptosis than $\mathrm{BO}(\mathrm{p}<0.01)$ and $\mathrm{CP}(\mathrm{p}<0.05)$ shown by TUNEL staining (Figure 4$)$.

Due to the neurotoxic effect of the cells, when the phase, light and electron microscope images were examined, decrease in cell volume, chromatin condensation, cytoplasmic vacuoles and fragmentations were observed as the signs of cell death. It was observed that the cells made cytoplasmic projections in the form of lamellipodia (Figure 5).

\section{Discussion}

Widely used in agriculture, synthetic pesticides control harmful pests and prevent crop yield losses and product damage. These may have undesirable effects to health and

a

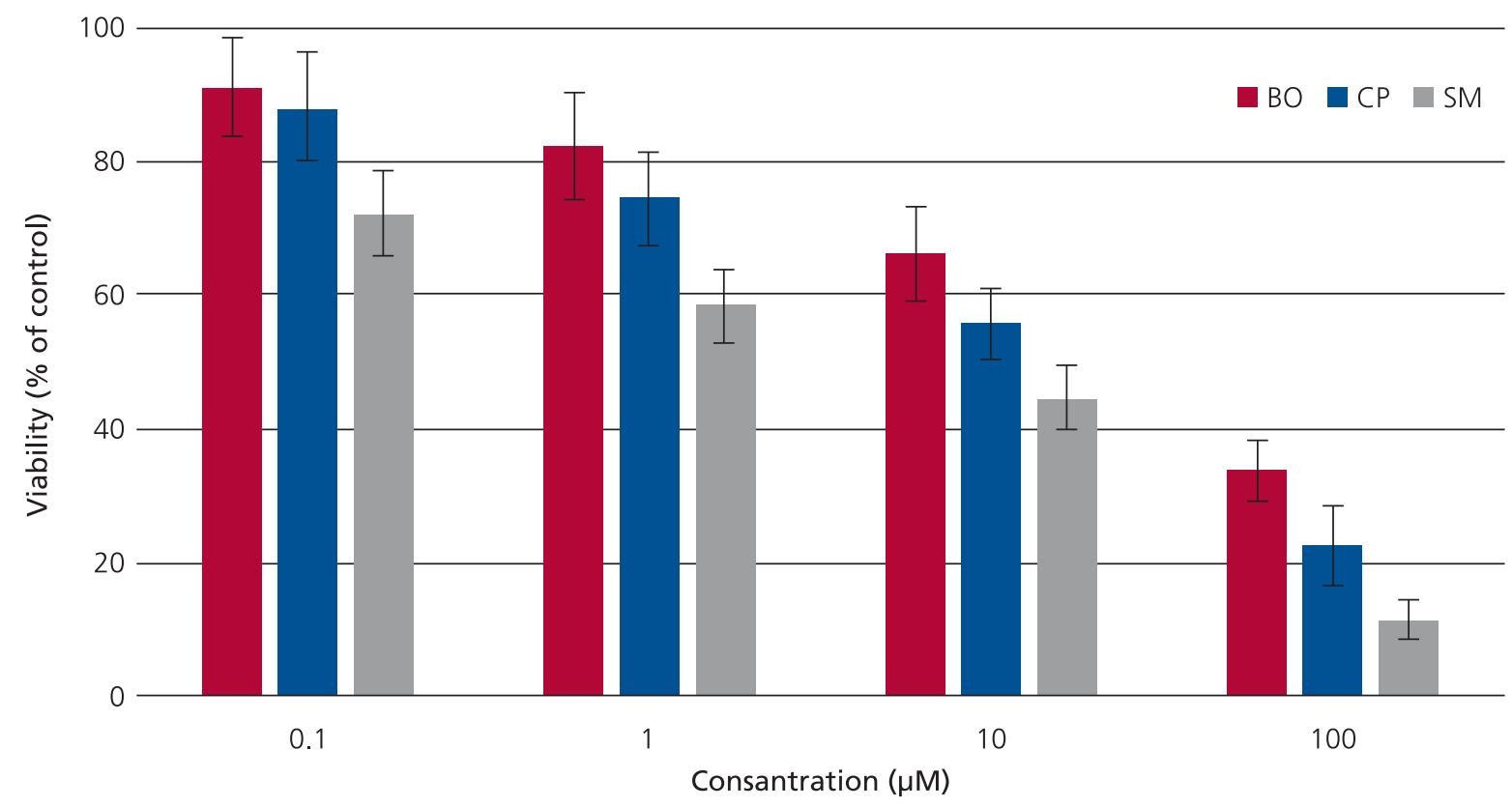

b

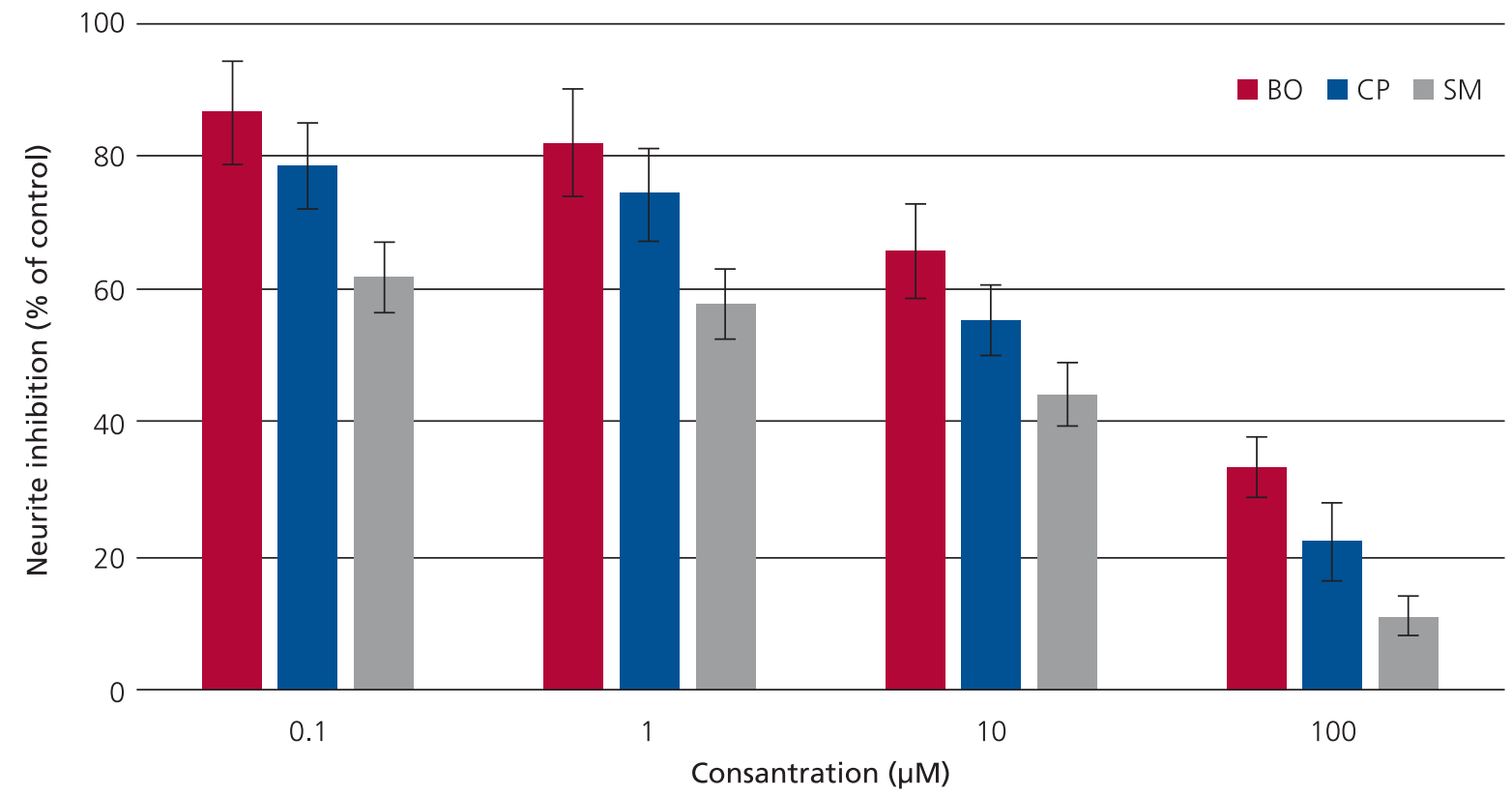

Figure 2 (a) The IC50 doses of the pesticides administered in the proliferation stage and determined by MTT; (b) Neurite inhibitions of differentiated cells after the second 24 hours of application were determined by NST. 
environment, due to their high biological activity and, in certain cases, long persistence in the nature. ${ }^{[4]}$ Environmental pollution caused by agricultural pesticides and resulting health problems are not fully known. The
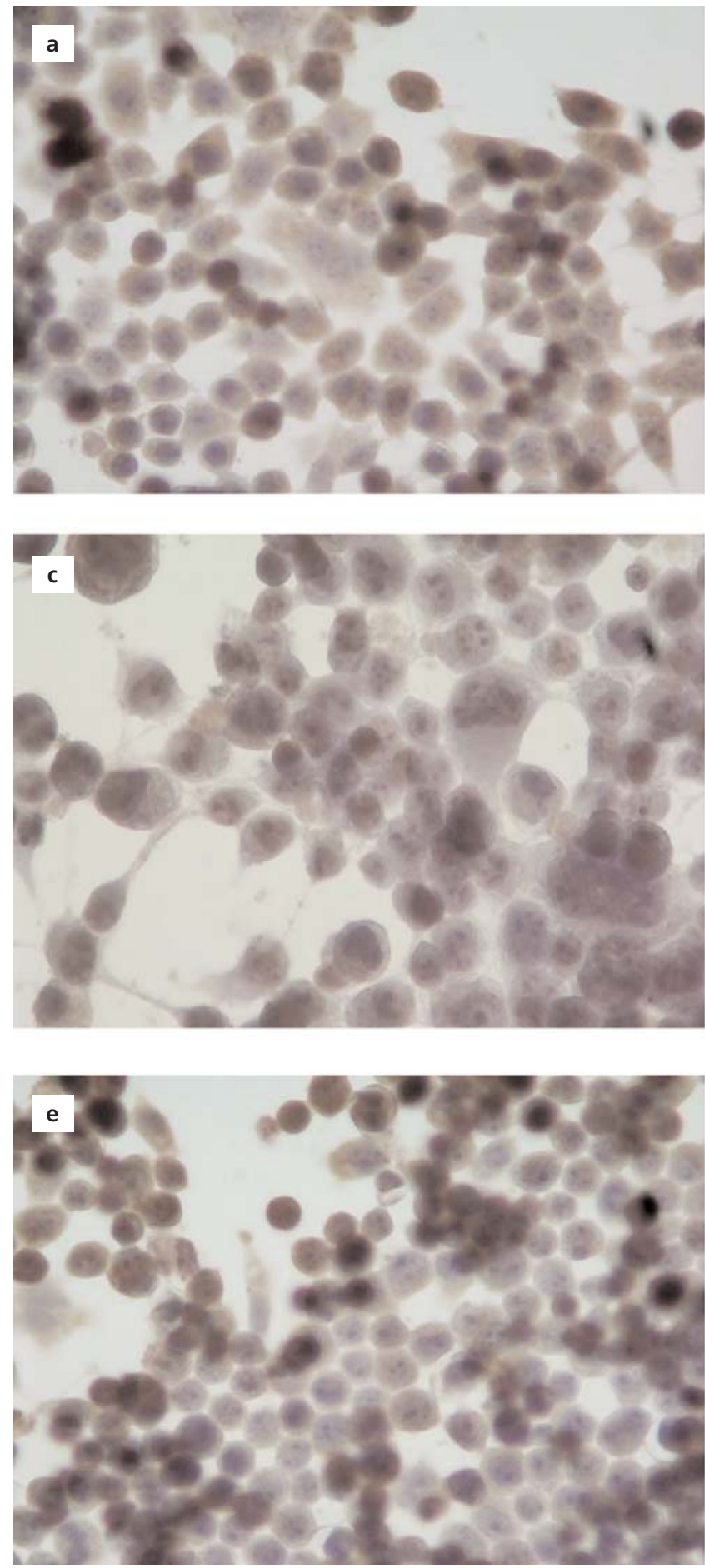

neurotoxic effect that agricultural pesticides can show in adults can be much more serious and problematic in children in the developmental period. This effect, called developmental neurotoxicity, is thought to be much more
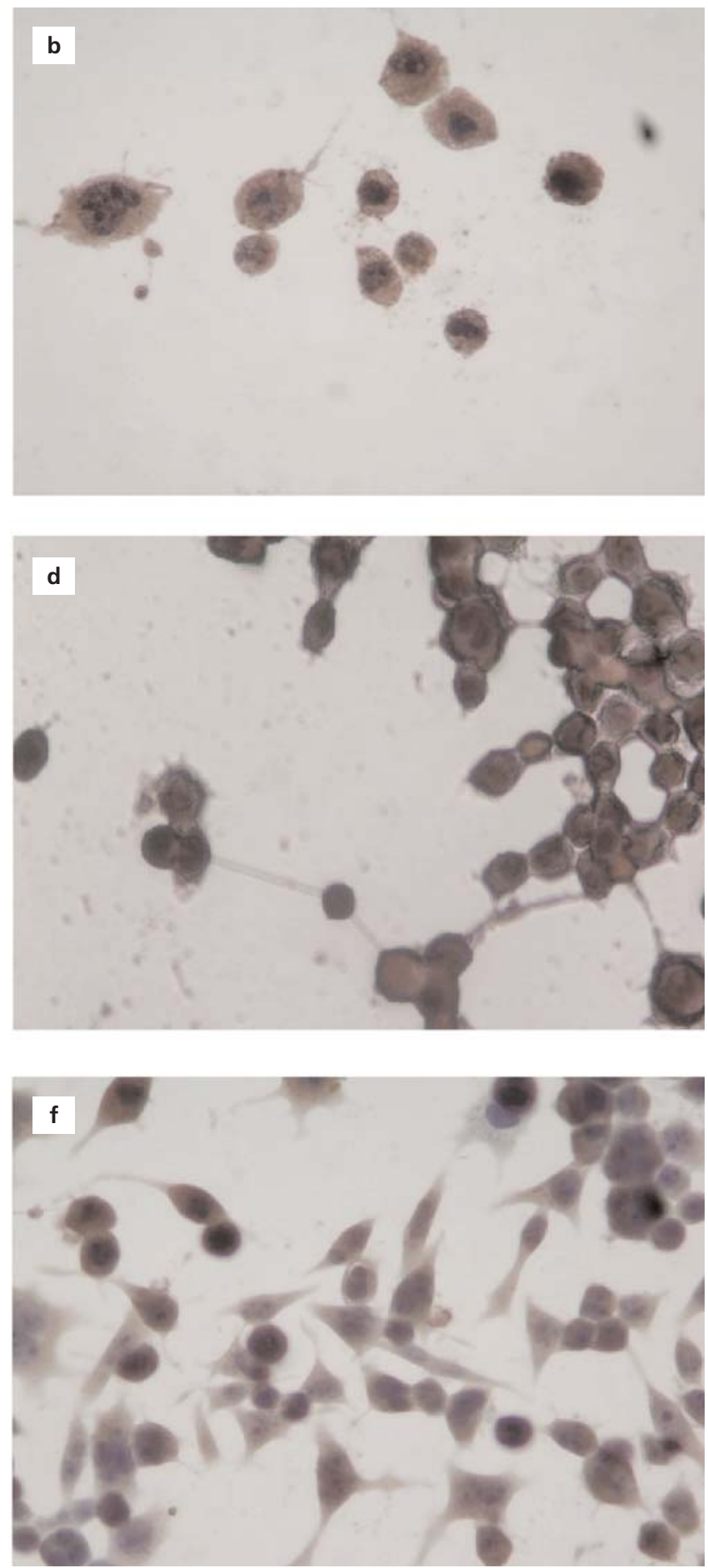

Figure 3. (a-f) At IC50 doses, the eNOS and iNOS expressions of the cells were shown by immunocytochemistry; $\times 200$. 


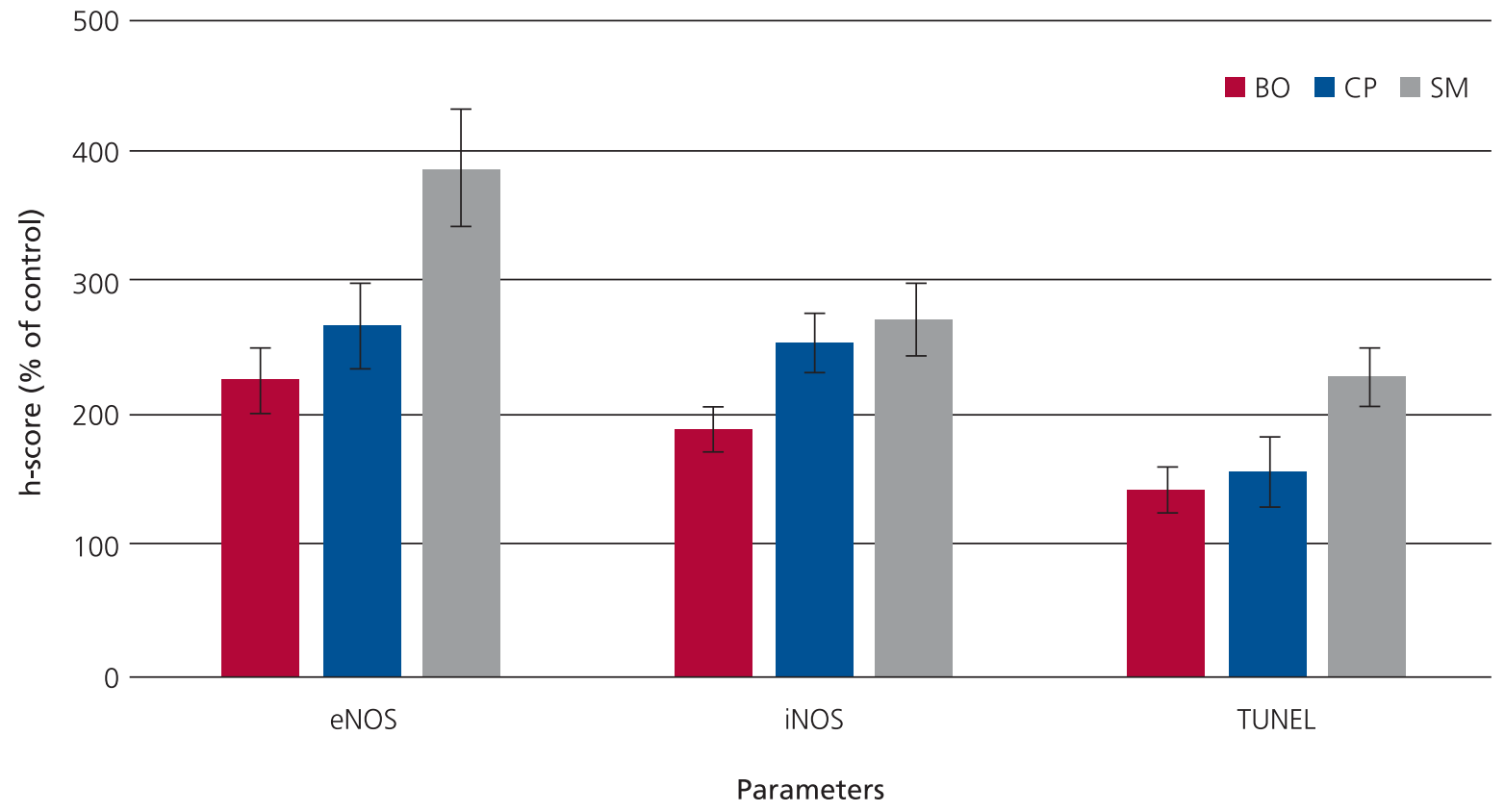

Figure 4. Oxidative stress was determined by h-score and apoptosis was determined by apoptotic index for the effect of the pesticide.

severe and irreversible. This is important in terms of developing diagnostic tests to investigate and prevent environmental pollution-related public health problems. Classical toxicity methods performed for this purpose are important for acute and effective toxicity. However, methods that can be used in terms of chronic toxicity are not many and one of them is neurite inhibition. In this method, due to the inhibition of the neuron's classical elongation ability, a moderate toxic effect is detected when the cell is alive. The onset of degeneration of the neuron exposed to toxic effect occurs with the disruption of the synapse and the loss of the tropic factor support. If toxic effect develops slowly, neurite prolongation is inhibited. This condition is associated with microtubules and neurofilament proteins. To demonstrate this moderate neurotoxic effect for agricultural pesticides, we used MTT for proliferation and cell survival, immunohistochemistry for oxidative stress and TUNEL for apoptosis. We showed that the moderate neurotoxicity had a proliferative effect as the MTT value decreased, and an oxidative stress effect as the h-score of NOS increased and that it was associated with TUNEL labeling through apoptosis.

The increasing use of agricultural industrial products poses a significant threat to environmental pollution. Despite all the rules and measures taken according to European data, hundreds of pesticides are still widely used. The dose of pesticides in one out of every twenty food items is more than the accepted level. Pesticides adversely affect children's development and in urine analysis, this toxic effect has been shown to be at varying degrees. Pesticides' contribution to environmental pollution is seen by detecting their presence in rivers, groundwater, soil, air, plants, and human and animal tissues proves pesticides' contribution to environmental pollution. Despite all the precautions taken, their toxic effects are observed, and the

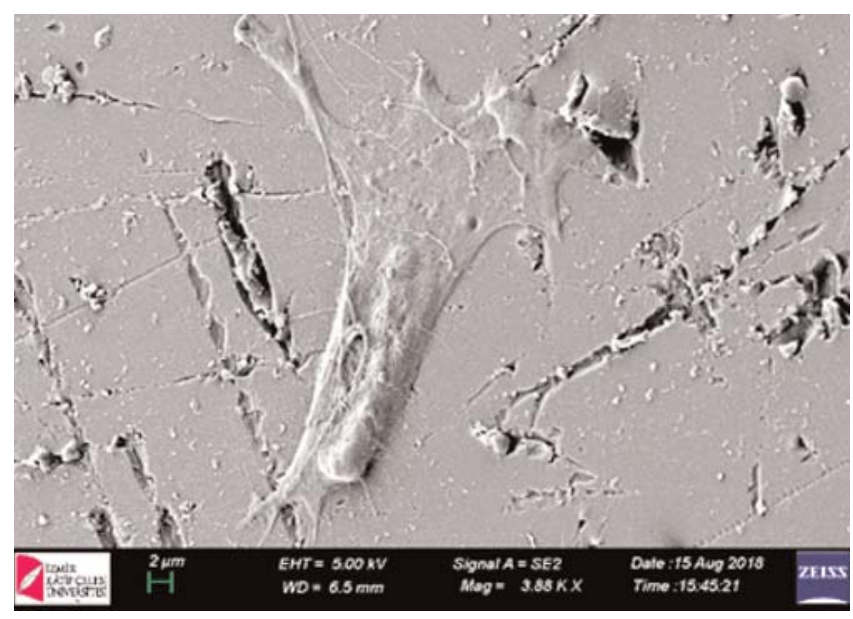

Figure 5. SEM images from proliferation, differentiation, neurite extension and apoptosis. There was decrease in cell volume, chromatin condensation, cytoplasmic vacuoles and fragmentations were observed as the signs of cell death. 
brain and neurons are the most critical organs among possible target organs. ${ }^{[15]}$ Therefore, different agricultural product that we were investigated for moderate toxicity from environmental pollution could be very important to human health.

It is more meaningful to reveal their possible effects in the culture environment due to the difficulties in conducting in vivo studies, and ethical concerns. While exposure lasting $\geq 90$ days is considered chronic in in vivo toxicity, its equivalent in the culture medium is the cell's undergoing neurite inhibition before it dies, which can be demonstrated with a three-day culture study. ${ }^{[15]}$ In a study conducted to investigate developmental neurotoxicity, it was found that neurite elongation was inhibited in PC12 cell line at nontoxic concentrations of a pesticide species. Dithiocarbonate fungicides were found to cause copper-dependent oxidative stress and neurotoxic effect with ROS production due to mitochondrial dysfunction. In addition, glutamate was thought to lead to a neurotoxic effect by affecting vesicular transport. It has been shown that apoptotic cell death due to toxic effect occurs due to intracellular calcium. It was also found that peripheral neuropathy and parkinsonismlike extrapyramidal effects occurred in toxicity-induced chronic exposure. ${ }^{[23]}$ In the neuron degenerated by toxic factors such as fungal pesticides, disruption of synapse, affection of perineurium, and decrease in trophic factors occur. The extent of the damage is related to the severity, time and continuity of the toxic agent. Neurotoxic effect occurs rapidly or slowly and affects the cell at different levels. Inhibition of neurite elongation is seen with a slow progressing moderate neurotoxic effect, and it occurs by the impairment of axonal transport. It is thought that the neurotoxic effect due to agricultural antifungal pesticides occurs in a similar way in our experiments. In a study in which the neurotoxic effects of agricultural pesticides were investigated in the culture environment, it was shown that they had a moderate neurotoxic effect related to dose and duration, consistent with our culture results.

It was determined that mitochondrial respiration complex and similarly the electron carrier ubiquinone or coenzyme Q were among the mechanisms used. Decreased ATP production and mitochondrial membrane depolarization were shown to cause cell death via increased cytosolic calcium. It was found that the different action mechanism shown in this way in cortical neurons cultured with new fungicides exerts a neurotoxic effect in relation to calcium channels. It was thought that calcium channel blockers would have a neuroprotective effect in this sense. Half of the cells were found to be viable despite the extended exposure times. In a comparison, that neurons were exposed to toxic effect in less concentrations than were lymphocytes indicated the importance of the nervous system in terms of health problems. It was observed that the delayed neurotoxic effect seen especially in organophosphates occurs clinically, similar to its occurrence as in the culture medium. ${ }^{[24]}$ In many cases, this condition results with neuropathy. Excitotoxicity and neuroinflammation are seen in alcohol-induced neurotoxic effect and are associated with proinflammatory cytokines. It was understood that oxidative stress and apoptosis mechanisms were used in the moderate neurotoxic effect that occurred here. ${ }^{[2]}$ Similar mechanisms were determined in the neurotoxic effect of glutamate. It has been reported that the neuroprotective effect of many different pesticides occurs through caspase 3 inhibition, and that neural damage due to decreased apoptosis is regressed. There are studies indicating that antioxidanteffective drugs similarly reduce neuron damage with calcium dependent mechanisms and that this situation is observed in the clinic situation. ${ }^{[5,15]}$ Similar to these experiments, we found apoptosis in our neurons due to agricultural products which may related to calcium metabolism.

There are studies investigating the responses of differentiated and undifferentiated cells in neuronal cell lines to demonstrate the neurotoxic effect. The response seen in differentiated cells against the neurotoxic effect shown by MTT, which is caused by the proliferation of undifferentiated cells, may be a different mechanism demonstrated by morphological and enzymatic methods. In a study, the neurotoxic effect for cylindrospermopsin was observed with changes in the form of acetylcholine esterase and apoptosis. The increase in oxidative stress causing apoptosis has been shown to be associated with changes in acetylcholine esterase activity. In addition, the authors thought that the clinical response of the in vitro neurotoxicity was related to the transition of the toxic agent to the blood-brain barri$\mathrm{er}^{[28,29]}$ The neurotoxic effect of agricultural products on the factors other than the target is important. The toxic effect of imidacloprid used to protect wheat on worms and the related environmental pollution has been shown in many studies. ${ }^{[2,27]}$ These studies indicated that apoptotic neurons due to agricultural products depend on acetylcholine esterase related alterations.

In earlier studies, it was shown that the morphology of cell size, shape and neurite lengths might change by substrate type and microscope. It was clear after proper staining, that the thin cell processes extending on the tissue culture surface showed classical neuronal behavior. We observed that the overall cell shape evolved to the direction of neurons, with several narrow extensions and cytosol appears more evenly extending all around its edges. Therefore, neuron-like cells kept their characteristics under tSEM examination. The cell adhesion and number of cells were sufficient to examine the ultrastructure of the neurons. ${ }^{[11,26]}$ 


\section{Conclusion}

Neurite inhibition may be important in early recognition for detecting and preventing the neurotoxic effect of pesticides. NST is an important in vitro test that can predict the long-term effects of neurotoxic agents. In the present study, antifungals used as pesticides were shown to have moderate neurotoxic effects in varying degrees. This means that pesticides may behave toxic in permitted limits for chronic exposure. In further studies, it will be possible to demonstrate other neurotoxic factors and to test antioxidant and antiapoptotic neuroprotective agents that can reduce neural damage. Thus, the potential of using neuroprotective agents in the clinic will increase the quality of life of patients.

\section{Conflict of Interest}

The authors declare that they have no known competing financial interests or personal relationships that could have appeared to influence the work reported in this paper.

\section{Author Contributions}

EMK: design, analysis, revising the draft, approval of the final version of the manuscript; TÖ \& DK: data collection; İT: analysis, design, revising the draft, approval of the final version of the manuscript.

\section{Ethics Approval}

No ethics approval needed.

\section{Funding}

This research did not receive any specific grant from funding agencies in the public, commercial, or non-profit sectors.

\section{References}

1. Yoshida M, McGregor D. Cyantraniliprole. In Pesticide residues in food 2013. Joint FAO/WHO Meeting on Pesticide Residues. Report of the Joint Meeting of the FAO Panel of Experts on Pesticide Residues in Food and the Environment and the WHO Core Assessment Group on Pesticide Residues. Geneva, Switzerland, September 17-26 2013. Rome: FAO; 2014. p. 131-76.

2. EFSA Panel on Nutrition, Novel Foods and Food Allergens (NDA); Truck D, Castenmiller J, De Henauw S, Hirsch-Ernst KI, Kearney J, Maciuk A, Mangelsdorf I, McArdle HJ, Naska A, Pelaez C, Pentieva K, Siani A, Thies F, Tsabouri S, Vinceti M, Cubadda F, Frenzel T, Heinonen M, Marchelli R, Neuhauser-Berthold M, Poulsen M, Prieto Maradona M, Schlatter JR, van Loveren H, Ververis E, Knutsen HK. Scientific Opinion on the safety of dried yellow mealworm (Tenebrio molitor larva) as a novel food pursuant to regulation (EU) 2015/2283. EFSA NDA Panel (EFSA Panel on Nutrition, Novel Foods and Food Allergens). EFSA J 2021;19(1): e06343.1-29.
3. European Food Safety Authority (EFSA). Conclusion on the peer review of the pesticide risk assesment of the active substance spiromesifen. EFSA J 2007;5(7):e105.1-69.

4. European Food Safety Authority (EFSA). Conclusion on the peer review of the pesticide risk assessment of the active substance cyantraniliprole. EFSA J 2014;12899.e03814.1-249.

5. Regueiro J, Olguín N, Simal-Gándara J, Suñol C. Toxicity evaluation of new agricultural fungicides in primary cultured cortical neurons. Environ Res 2015;140:37-44.

6. El Merhie A, Salerno M, Toccafondi C, Dante S. Neuronal-like response of N2a living cells to nanoporous patterns of thin supported anodic alumina. Colloids Surf B Biointerfaces 2019;178:32-7.

7. Wang H, Meng Z, Liu F, Zhou L, Su M, Meng Y, Zhang S, Liao X, Cao Z, Lu H. Characterization of boscalid-induced oxidative stress and neurodevelopmental toxicity in zebrafish embryos. Chemosphere 2020;238:124753.

8. Çayır A, Coskun M, Coskun M. Micronuclei, nucleoplasmic bridges, and nuclear buds induced in human lymphocytes by the fungicide signum and its active ingredients (boscalid and pyraclostrobin). Environ Toxicol 2014;29:723-32.

9. Bielza P, Moreno I, Belando A, Grávalos C, Izquierdo J, Nauen R. Spiromesifen and spirotetramat resistance in field populations of Bemisia tabaci Gennadius in Spain. Pest Manag Sci 2019;75:45-52.

10. McLean WG. Holme AD, Janneh O, Southgate A, Howard CV, Reed MG. The effect of benomyl on neurite outgrowth in mouse N2A and human SH-SY5Y neuroblastoma cells in vitro. Neurotoxicology 1998;19:629-32.

11. Smith SL, Sadler CJ, Dodd CC, Edwards G, Ward SA, Park BK, McLean WG. The role of glutathione in the neurotoxicity of artemisinin derivatives in vitro. Biochem Pharmacol 2001;15:40916.

12. Vural K, Tuglu MI. Neurotoxic effect of statins on mouse neuroblastoma NB2a cell line. Eur Rev Med Pharmacol Sci 2011;15:98591.

13. Ferrari E, Cardinale A, Picconi B, Gardoni F. From cell lines to pluripotent stem cells for modelling Parkinson's disease. J Neurosci Methods 2020;340:108741.

14. Axelrad JC, Howard CV, McLean WG. Interactions between pesticides and components of pesticide formulations in an in vitro neurotoxicity test. Toxicology 2002;173:259-68.

15. Voorhees JR, Rohlman DS, Lein PJ, Pieper AA. Neurotoxicity in preclinical models of occupational exposure to organophosphorus compounds. Front Neurosci 2017;10:590.

16. Vural K, Seyrek O. The neuroprotective effect of pioglitazone on NB2a mouse neuroblastoma cell culture. Kafkas Üniversitesi Veteriner Fakültesi Dergisi 2019;25:1-8.

17. Klebe RJ, Chen T, Ruddle FH. Mapping of a human genetic regulator element by somatic cell genetic analysis. Proc Natl Acad Sci USA 1970;66:1220-7.

18. LePage KT, Dickey RW, Gerwick WH, Jester EL, Murray TF. On the use of neuro-2a neuroblastoma cells versus intact neurons in primary culture for neurotoxicity studies. Crit Rev Neurobiol 2005;17:27-50.

19. Lee MK, Nikodem VM. Differential role of ERK in cAMP-induced Nurr1 expression in N2A and C6 cells. Neuroreport 2004;15:99_ 102.

20. Axelrad JC, Howard CV, McLean WG. The effects of acute pesticide exposure on neuroblastoma cells chronically exposed to diazinon. Toxicology 2003;185:67-78. 
21. Mete M, Aydemir I, Ünlü Ünsal Ü, Duransoy YK, Tuğlu İM, Selçuki M. Neuroprotective effects of bone marrow-derived mesenchymal stem cellsand conditioned medium in mechanically injured neuroblastoma cells. Turk J Med Sci 2016;46:1900-7.

22. Sachana M, Flaskos J, Alexaki E, Glynn P, Hargreaves AJ. The toxicity of chlorpyrifos towards differentiating mouse N2a neuroblastoma cells. Toxicol In Vitro 2001;15:369-72.

23. Bjørling-Poulsen M, Andersen HR, Grandjean P. Potential developmental neurotoxicity of pesticides used in Europe. Environ Health 2008;7:50.

24. Hargreaves AJ, Sachana M, Flaskos J. The use of differentiating N2a and C6 cell lines for studies of organophosphate toxicity. In: Aschner M, Suñol C, Bal-Price A, editors. Neuromethods, Vol 56: Cell culture techniques. New York ((NY): Springer; 2011. p. 26991.

25. Bilir EK, Tutun H, Sevin S, Kismali G, Yarsan E Cytotoxic effects of Rhododendron ponticum L. extract on prostate carcinoma and

ORCID ID:

E. M. Karakayalı 0000-0001-5779-4102; D. Kekeç 0000-0003-2192-2058; T. Önal 0000-0002-3650-4046; I. Tuğlu 0000-0002-0569-8415 adenocarcinoma cell line (DU145, PC3). Kafkas Üniversitesi Veteriner Fakültesi Dergisi 2018;24:451-7.

26. Lau K, McLean WG, Williams DP, Howard CV. Synergistic interactions between commonly used food additives in a developmental neurotoxicity test. Toxicol Sci 2006;90:178-87.

27. Qi Y, Cao X, Abd El-Aty AM, Ma C, Li H, Jiang Z, She Y, Wang S, Wang J, Yang S. A magnetic zeolitic imidazolate framework nanohybrid for fast and efficient extraction of clothianidin, imidacloprid, acetamiprid, and thiacloprid in water. J Nanosci Nanotechnol 2019; 19:3310-8.

28. Damalas CA, Koutroubas SD. Farmers' exposure to pesticides: toxicity types and ways of prevention. Toxics 2016;4:1.

29. Hinojosa MG, Gutiérrez-Praena D, Prieto AI, Guzmán-Guillén R, Jos A, Cameán AM. Neurotoxicity induced by microcystins and cylindrospermopsin: a review. Sci Total Environ 2019;10:668:54765 .

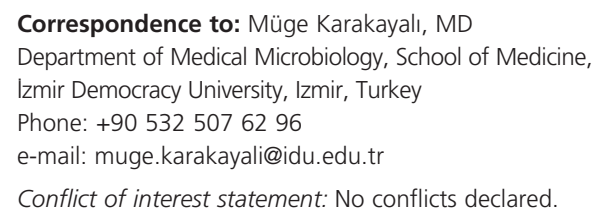

This is an open access article distributed under the terms of the Creative Commons Attribution-NonCommercial-NoDerivs 4.0 Unported (CC BY-NCND4.0) Licence (http://creativecommons.org/licenses/by-nc-nd/4.0/) which permits unrestricted noncommercial use, distribution, and reproduction in any medium, provided the original work is properly cited. How to cite this article: Karakayalı EM, Kekeç D, Önal T, Tuğlu İ. Investigation of the moderate toxicity of agricultural pesticides cyantraniliprole, boscalid and spiromesifen in vitro using neurotoxicity screening test. Anatomy 2021;15(1):1-10. 